\title{
Host and Environmental Factors Affecting the Intestinal Microbiota in Chickens
}

\author{
Jannigje G. Kers ${ }^{1,2 *}$, Francisca C. Velkers ${ }^{1}$, Egil A. J. Fischer ${ }^{1}$, Gerben D. A. Hermes ${ }^{2}$, \\ J. A. Stegeman' ${ }^{1}$ and Hauke Smidt ${ }^{2}$
}

${ }^{1}$ Department of Farm Animal Health, Faculty of Veterinary Medicine, Utrecht University, Utrecht, Netherlands, ${ }^{2}$ Laboratory of Microbiology, Wageningen University \& Research, Wageningen, Netherlands

The initial development of intestinal microbiota in poultry plays an important role in production performance, overall health and resistance against microbial infections. Multiplexed sequencing of $16 \mathrm{~S}$ ribosomal RNA gene amplicons is often used in studies, such as feed intervention or antimicrobial drug trials, to determine corresponding effects on the composition of intestinal microbiota. However, considerable variation of intestinal microbiota composition has been observed both within and across studies. Such variation may in part be attributed to technical factors, such as sampling procedures, sample storage, DNA extraction, the choice of PCR primers and corresponding region to be sequenced, and the sequencing platforms used. Furthermore, part of this variation in microbiota composition may also be explained by different host characteristics and environmental factors. To facilitate the improvement of design, reproducibility

\section{OPEN ACCESS}

Edited by: Francesca Turroni, Università degli Studi di Parma, Italy

Reviewed by:

Robert J. Moore,

RMIT University, Australia

Cristiano Bortoluzzi,

University of Georgia, Georgia

${ }^{*}$ Correspondence:

Jannigje G. Kers

j.g.kers@uu.n

Specialty section: This article was submitted to Microbial Symbioses,

a section of the journal

Frontiers in Microbiology

Received: 23 October 2017

Accepted: 31 January 2018

Published: 16 February 2018

Citation:

Kers JG, Velkers FC, Fischer EAJ,

Hermes GDA, Stegeman JA and

Smidt $H$ (2018) Host and Environmental Factors Affecting the Intestinal Microbiota in Chickens.

Front. Microbiol. 9:235.

doi: 10.3389/fmicb.2018.00235 and interpretation of poultry microbiota studies, we have reviewed the literature on confounding factors influencing the observed intestinal microbiota in chickens. First, it has been identified that host-related factors, such as age, sex, and breed, have a large effect on intestinal microbiota. The diversity of chicken intestinal microbiota tends to increase most during the first weeks of life, and corresponding colonization patterns seem to differ between layer- and meat-type chickens. Second, it has been found that environmental factors, such as biosecurity level, housing, litter, feed access and climate also have an effect on the composition of the intestinal microbiota. As microbiota studies have to deal with many of these unknown or hidden host and environmental variables, the choice of study designs can have a great impact on study outcomes and interpretation of the data. Providing details on a broad range of host and environmental factors in articles and sequence data repositories is highly recommended. This creates opportunities to combine data from different studies for meta-analysis, which will facilitate scientific breakthroughs toward nutritional and husbandry associated strategies to improve animal health and performance.

Keywords: gut microbiota, poultry, confounding factors, microbiome, gut health, 16S rRNA

\section{INTRODUCTION}

In recent years several articles have been published on the intestinal microbiota composition of chickens and its associations with production and health (Nava et al., 2007; Brisbin et al., 2008; Kohl, 2012; Stanley et al., 2012a; Yeoman et al., 2012). For instance, some studies have described differences in bacterial species abundance for broilers with high vs. low growth and feed efficiency 
(Stanley et al., 2012a; Singh et al., 2014). Another important topic in microbiota research is Clostridium perfringens-associated necrotic enteritis that can cause severe production losses and disease in broilers, and can cause foodborne illness in humans (Hook et al., 1996; Van Immerseel et al., 2004). Necrotic enteritis is associated with perturbations in microbiota composition, but whether these are cause or effect of $C$. perfringens proliferation remains unclear (Stanley et al., 2012b; Antonissen et al., 2016; Moore, 2016). Also, the ban on antibiotic growth promoters in the European Union has prompted research into developing alternative nutritional strategies aiming at stimulation of beneficial microbiota in chickens (Stanley et al., 2014). These examples illustrate that it is essential to increase our biological understanding of the host-microbe interactions, which may eventually result in effective strategies to promote sustainable poultry production.

Although much progress has been made in this rapidly expanding research field, researchers using next generation sequencing (NGS) tools have reported large differences in microbiota composition across and within studies (Stanley et al., 2013; Brooks et al., 2015; Reardon, 2016). A meta-analysis of gut microbiota studies across different avian species showed that a large factor contributing to the observed variation in avian intestinal microbiota composition was the study itself (Waite and Taylor, 2014). Within the same study, differences in intestinal microbiota composition may also occur across independent poultry trials, even when the research conditions are carefully controlled and intended to be similar across trials (Stanley et al., 2013; Thibodeau et al., 2017). Comparison of the outcomes of microbiota studies might be hampered by differences in technical aspects, biological variation within and between hosts, and environmental factors (Lozupone et al., 2013; Brooks et al., 2015; Laukens et al., 2016). Multiplex sequencing of $16 \mathrm{~S}$ ribosomal RNA (rRNA) gene amplicons, which is often used to profile the composition of the intestinal microbiota, is associated with technical variation. Differences in the sequencing platforms used, the choice of PCR primers and corresponding region to be sequenced, the number of PCR cycles, DNA extraction protocols, and the storage of samples can create variation in outcomes between studies. These technical factors have been reviewed previously (Pissavin et al., 2012; Lozupone et al., 2013; Brooks et al., 2015; Hermes et al., 2015; Laukens et al., 2016; Allali et al., 2017) and are therefore beyond the scope of this review. The aim of this review is to provide an overview of poultry-specific host and environmental factors that affect the composition of the intestinal microbiota of poultry, and to create awareness of confounding factors in poultry microbiota studies. Knowledge of these factors will enable the improvement of design and reproducibility of outcomes of poultry microbiota studies. An overview of biological and environmental factors potentially influencing chicken microbiota composition described in the literature is shown in Figure 1. In the following sections, known effects of host characteristics and environmental factors on intestinal microbiota will be described, followed by a discussion of the potential implications of these confounding factors for microbiota research in poultry.

\section{HOST CHARACTERISTICS INFLUENCING INTESTINAL MICROBIOTA IN POULTRY}

\section{Development of the Chickens}

One-day-old broiler chicks already carry a community of microorganisms in their intestinal tract (Ballou et al., 2016). Microorganisms can be acquired in the pre-hatching phase, directly from the mother in the oviduct of the hen (Gantois et al., 2009) or from the environment through the pores in the eggshell (Cason et al., 1994; Roto et al., 2016). In a recent publication it was shown that broiler eggs contaminated with cecal microbiota on the egg surface of other birds reduced the bird-to-bird variation in the cecal microbiota composition after hatch but not the composition itself (Donaldson et al., 2017). This means that the cecal microbiota on the egg surface resulted in more similarity between the microbiota samples of the individual broilers, but the microbiota of the donors associated with high or low performance was not actually transferred to the newly hatched broilers. After hatch, the young chicks might be colonized before arriving at the farm by microbiota from the environment at the hatchery or during transport (Shapiro et al., 1949; Pedroso et al., 2005).

The microbiota composition may also be influenced by maternal antibodies supplied through the yolk. Maternal antibodies can provide protection against colonization by certain pathogens generally until 2 weeks post-hatch (Grindstaff et al., 2003; Hamal et al., 2006), and this may affect the chicks' intestinal microbiota. In mammals it is known that maternal antibodies can affect the interaction between intestinal bacteria and the immune system (Cebra, 1999). Although the mechanism behind the interaction of bacteria and the immune system is not exactly clear, the altered development of the immune system in germ-free animals suggests that it is at least partly shaped by the microbiota (Williams, 2014).

In chickens the intestinal microbiota richness, i.e., the number of different microbial taxa, increases during the first weeks of life (Gerard et al., 2008; Danzeisen et al., 2011; Ballou et al., 2016), while the individual variation in microbiota composition decreases as the chickens age (Crhanova et al., 2011). A compilation of $16 \mathrm{~S}$ rRNA gene amplicon sequencing data from cecal samples of two different broiler breeds (meat production) and layer-type chickens (egg production) shows variation at the phylum level across studies, and at different time points (Figures 2-4). This compilation is based on a systematic literature search. However, the limited number of articles with $16 \mathrm{~S}$ rRNA gene amplicon sequencing data, and the large methodological differences between poultry studies did not allow for accurate re-analyses of original raw data to provide figures that would represent a true meta-analysis of studies. Therefore only the relative abundance at phylum level of the chickens in groups not exposed to specific treatments (control groups) is summarized to illustrate some general differences in microbiota development with regard to breed and age. Firmicutes were the most abundant phylum across the two broiler breeds throughout the production period from 0 to 42 days of age (Figures 2, 3). It 


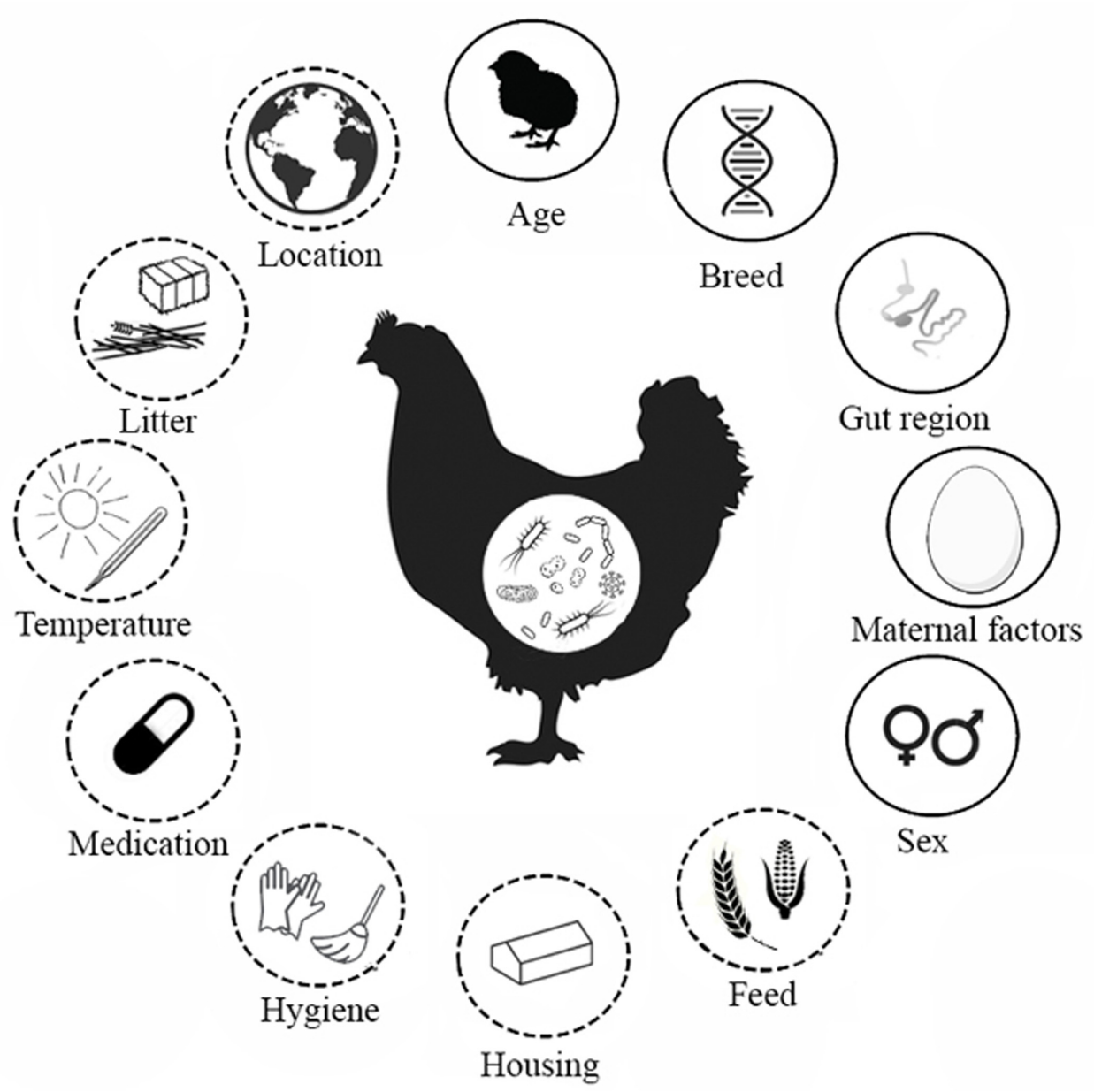

FIGURE 1 | Factors that affect the intestinal microbiota composition of chickens. Factors found in the literature that determine the development of the intestinal microbiota in broiler chickens. Solid line indicates host characteristics, dashed line indicates environmental factors. The gut regions comprise the crop, proventriculus, gizzard, duodenum, jejunum, ileum, caeca, large intestine and cloaca. Maternal factors include horizontal transmission, vertical transmission and maternal antibodies.

is striking that Firmicutes were found to be the most abundant phylum on day 0 in meat-type chickens whereas Proteobacteria were most abundant in layer-type chickens (Figure 4). On day 0 the relative abundance of Proteobacteria in layer-type chickens was above $85 \%$ (Figure 4) (Ballou et al., 2016), whereas in meattype chickens this phylum only accounted for approximately $30 \%$ (Danzeisen et al., 2011) (Figure 2), and 5\% (Pedroso et al., 2016) (Figure 3). Firmicutes become the most abundant phylum also in layer-type chickens from day 7 onward (Figure 4). For humans it has been shown that facultative anaerobic Proteobacteria are the most abundant phylum in the first period of life (Reinhardt et al., 2009; De Filippo et al., 2010; Schwartz et al., 2012), which is also seen in laying hens (Videnska et al., 2014b; Ballou et al., 2016) but not in broilers. The variation in colonization pattern between layer-type and meat-type chickens might be explained by the differences in exposure to microbiota, husbandry factors, and feed composition, but biological differences between these chicken types are most likely to play an important role as well and will be discussed in the next section.

\section{Chicken Type and Breed}

The genetic background of the host has been recognized as a factor that might influence intestinal microbiota composition (Benson et al., 2010; Org et al., 2015; Schokker et al., 2015; Han et al., 2016b). Considerable physiological differences exist between layer-type and meat-type chickens. Over decades, breeding programs have selected laying hens for maximal egg production and broilers for maximal meat production. This has resulted in large differences in growth, with an average body weight of laying hens of $450 \mathrm{~g}$ compared to $2800 \mathrm{~g}$ at 6 weeks of age in broilers ${ }^{1}$. These chicken breeding programs seem to have affected intestinal physiology (Uni et al., 1996) and immune function (Simon et al., 2014). Morphological differences in the intestinal tissue between laying hens and broiler chickens with

\footnotetext{
${ }^{1}$ http://en.aviagen.com/assets/Tech_Center/Ross_Broiler/Ross-BroilerHandbook-2014i-EN.pdf,

http://www.hyline.com/UserDocs/Pages/36_COM_ENG.pdf, http://www.lohmanngb.co.uk/files/Classic-Colony-Manual-28-Mar-2011.pdf
} 


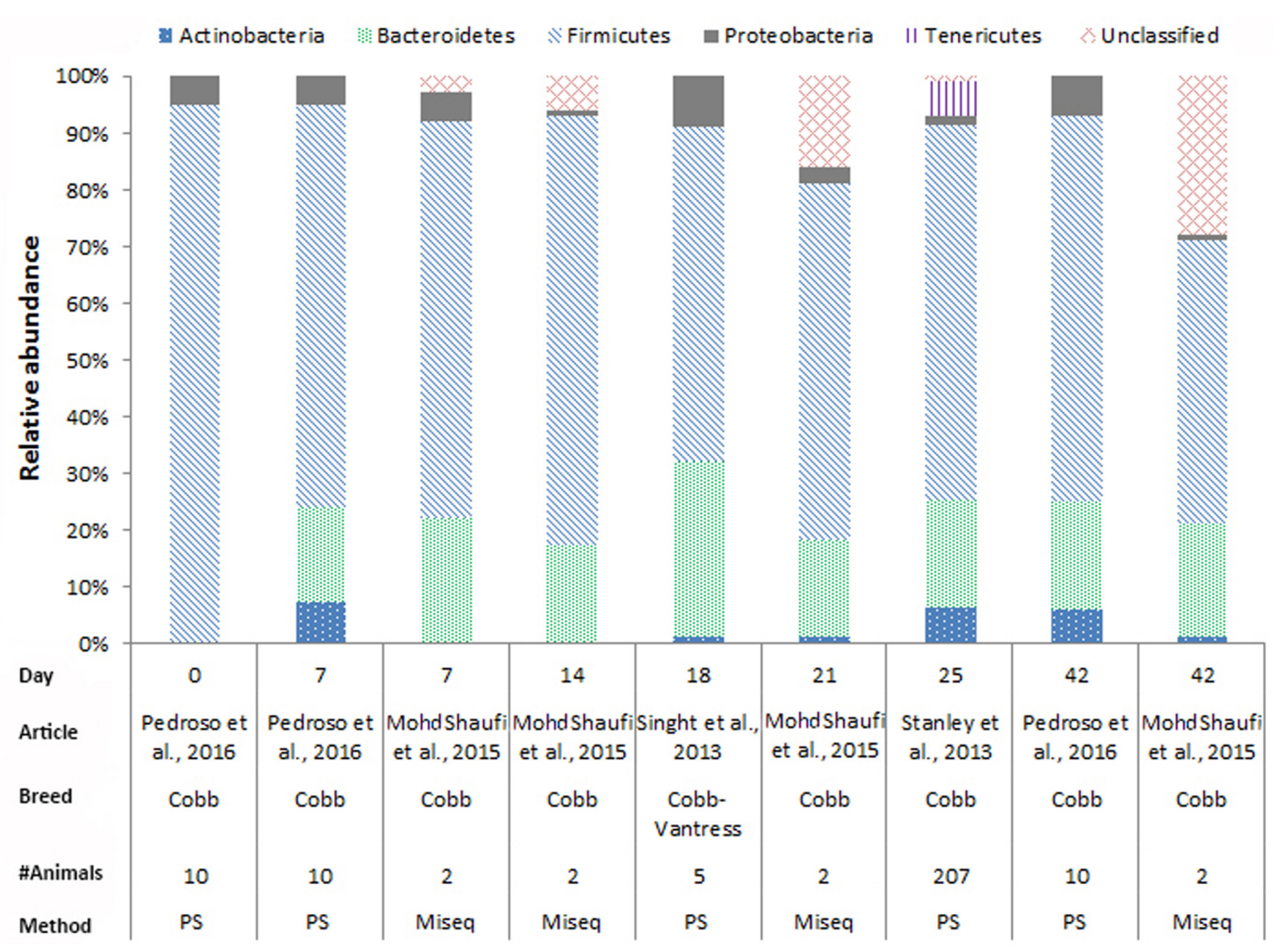

FIGURE 2 | The composition of the cecal microbiota in Cobb broilers at phylum level. General composition of the cecal microbiota in Cobb broilers across different ages, from control groups, not exposed to specific treatments. The data is from four different studies, based on $16 S$ rRNA 454 pyrosequencing (PS), $n=3$ and MiSeq sequencing $n=1$. Pedroso et al. (2016), Figure 7, stacked bar chart A was used. Mohd Shaufi et al. (2015), Figure 4, the last four bars were used. Singh et al. (2013), the data from Figure 1 was used. Stanley et al. (2013), the data from MG-RAST was used to combine the data from Figure 6.

respect to villus height, villus width, and crypt depth influence the intestinal absorptive area and have been associated with the higher body weight of broilers (Uni et al., 1996). Moreover, it has been shown that the expression of IgA, IgM, and IgY in the ileum is higher in broilers compared to laying hens (Simon et al., 2014). These and other differences in intestinal physiology and immune system development between laying hens and broiler chickens are likely to influence microbiota composition and vice versa. Studies on differences between broilers and laying hens with regard to microbiota composition are scarce. To our knowledge, only two studies compared the microbiota composition between broilers and laying hens. It should be noted, however, that the first study was done with 3-week-old broilers and 62-week-old laying hens (Videnska et al., 2014a). This large age difference, as well as the difference in exposure to microbes in the housing environment and substantial differences in the composition of the diet for broilers and laying hens, may also have influenced microbiota composition, which hampers conclusions on the effect of chicken type (Videnska et al., 2014a). In the second study, as expected, differences in the development of local immunity and the colonization pattern of commensal bacteria between chicken types were found, and these differences were also shown to significantly alter the response to inoculation with Campylobacter (Han et al., 2016b). This indicates that differences in chicken breeds or genetic lines can impact important study outcomes.

In addition to biological differences between layer-type and meat-type chickens, there are also differences within chicken breeds of the same chicken type. As a previous observational study has shown, broiler breed was a factor associated with colonization by antibiotic resistant strains of Escherichia coli (Persoons et al., 2011), and in an experimental study it was shown that different broiler breeds significantly differed in disease susceptibility to necrotic enteritis (Jang et al., 2013). In a study with different broiler breeds, hatched in the same hatchery, it was shown that each breed also had its own unique ileum microbiota composition at the age of 20 days (Kim et al., 2015). In 20-day-old Cobb broilers, Bacteroidetes were found in the ileum content, but were absent in Ross broilers. In turn, in Ross broilers, Actinobacteria were found in the ileum content, but not in Cobb broilers (Kim et al., 2015). Similar results were found in other studies, i.e., absence of Bacteroidetes and presence of Actinobacteria in Ross broilers at 21 days of age (Nakphaichit et al., 2011) and 25 days of age (Pourabedin et al., 2015), and Cobb broilers without Actinobacteria but with Bacteroidetes at 23 days of age (Mohd Shaufi et al., 2015). In contrast, in another recent study a relative abundance of $22 \%$ of Bacteroidetes was reported in the ileum of 18-day-old Ross broilers (Han et al., 2016a). The 


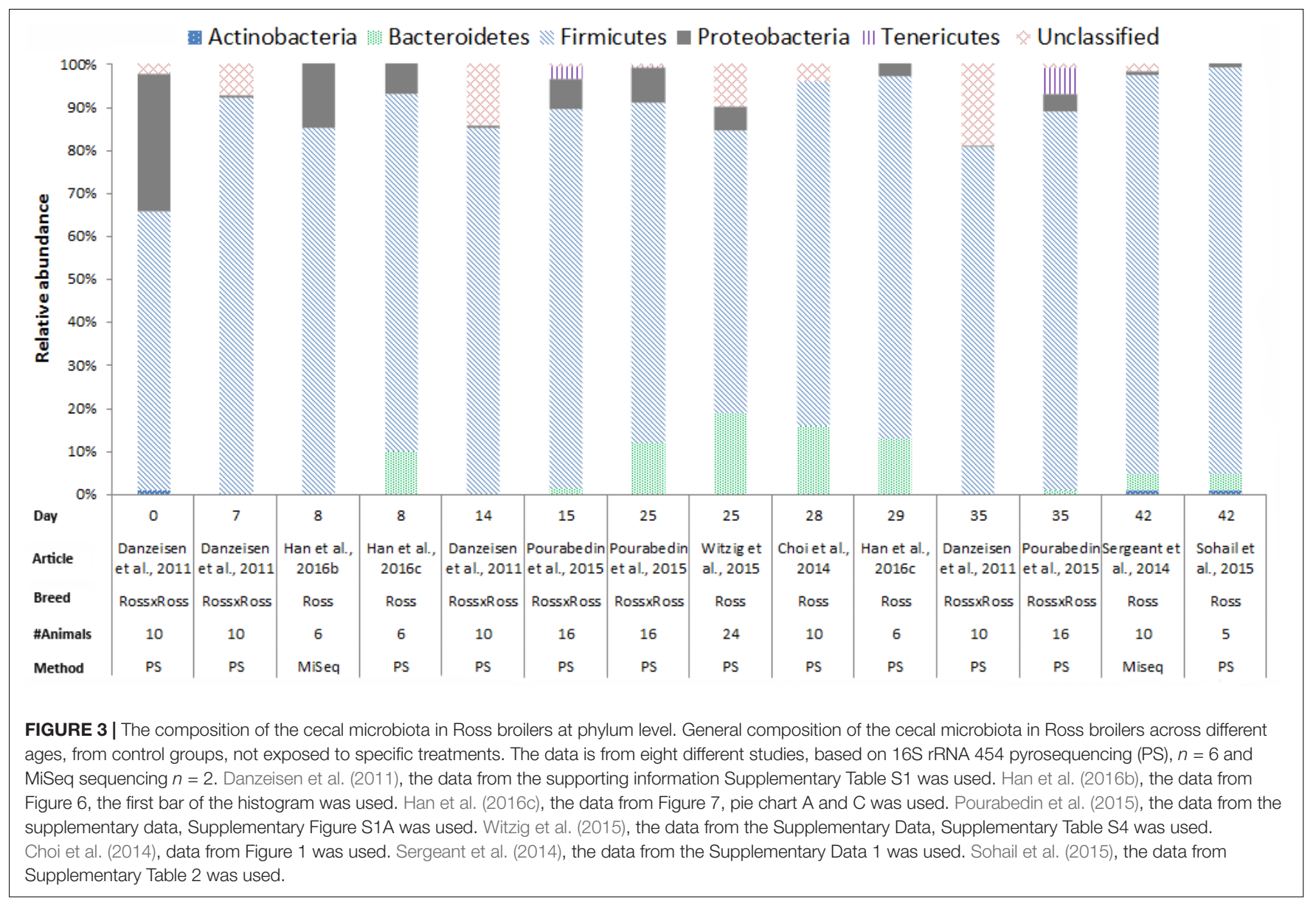

presence of Bacteroidetes in the latter study and absence in the other studies may be caused by inevitable differences in diet or other experimental conditions, the younger age at sampling, differences in sequencing technology; as pyrosequencing vs. Illumina MiSeq, or the differences in the primers used.

We compiled the data of studies for which 16S rRNA gene amplicon sequencing data of cecal samples was available for two broiler breeds (Figures 2, 3). This compilation shows that in cecal samples Actinobacteria are present in all four Cobb studies $(100 \%)$ and in three out of eight Ross studies (38\%), and that Bacteroidetes are present in all four Cobb studies (100\%) and in six out of eight Ross studies (75\%) (Figures 2, 3). These figures might suggest that breed influences the microbiota composition, but it is more likely that Cobb and Ross broilers had a different exposure to microbiota due to differences in parent flock or due to differences in the immune responses caused by differences in the genetic background (Emam et al., 2014; Schokker et al., 2015). Furthermore, it should be noted that, unfortunately, many articles on chicken microbiota data do not contain information about the breed (Qu et al., 2008; Corrigan et al., 2015; Lim et al., 2015; Schokker et al., 2015; Li et al., 2016; Oakley and Kogut, 2016; Lin et al., 2017).

Within certain broiler breeds, there is also a distinction between low and high body weight lines. As several studies have revealed, broilers from lines with low and high feed conversion ratio (FCR) show differences in their bacterial communities. In fecal samples, broiler lines with low FCR, indicating a more efficient use of feed for growth, showed higher counts for Lactobacillus compared to broilers lines with high FCR (Zhao et al., 2013; Meng et al., 2014; Mignon-Grasteau et al., 2015). Broiler line comparison in another study showed that the composition of the microbiota differed while microbial diversity did not, which might suggest that different chicken lines harbor different microorganisms for the same intestinal function (Schokker et al., 2015). The mechanisms behind the variation in intestinal microbiota between different broiler lines remain unclear, but it has been suggested that genetic background and the immune system influence establishment of gut microbiota after hatch (Schokker et al., 2015). Commercial selection programs for high production may result in comicroevolution of the microbiota and immune system of the host (Yang et al., 2017), although other factors, such as differences in exposure to microbial communities, cannot be excluded.

\section{Sex}

In poultry, sex difference is part of the disparate production system, because layer-type chicken flocks predominantly consist of hens, whereas in broiler flocks males and females are often raised together. Broiler males generally have a higher growth rate and lower FCR than broiler females. Differences in 


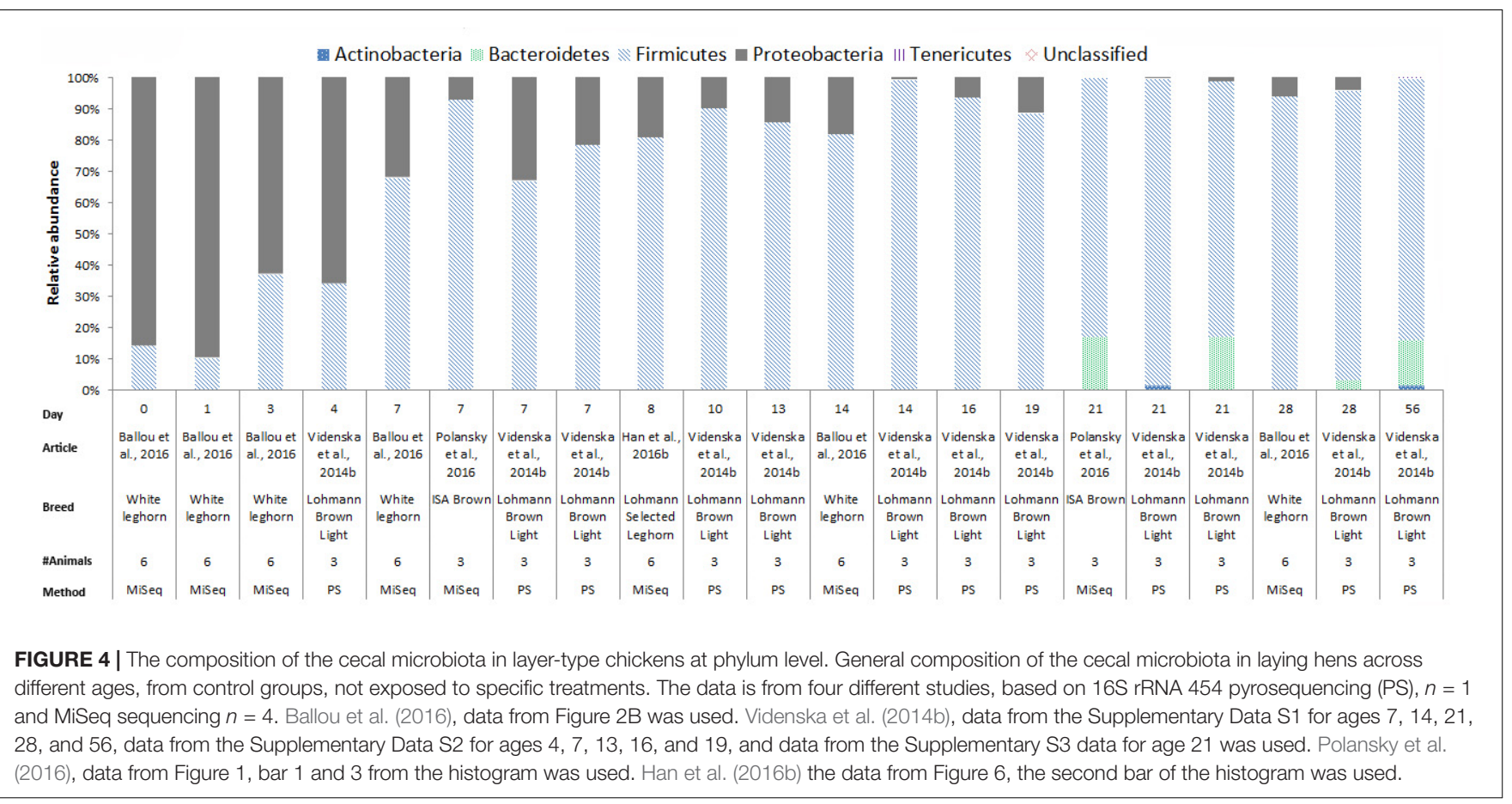

bacterial communities between male and female broilers are also influenced by non-growth related factors, because no differences in growth rate were observed until day 21 , whereas already at day 3 differences were observed in the intestinal microbiota composition (Lumpkins et al., 2008). In this study, the intestinal microbiota communities, determined by denaturing gradient gel electrophoresis (DGGE) of PCR-amplified 16S rRNA gene fragments, showed less than $30 \%$ similarity between male and females (Lumpkins et al., 2008). Another study, where female and male broilers (age 22 and 42 days) were compared using quantitative PCR (qPCR), showed differences in abundance of Lactobacillus salivarius, L. crispatus, L. aviarius, and E. coli in their ceca (Torok et al., 2013). These are four out of the five potential performance-related bacteria of the QPCR format used (Torok et al., 2013). In a study on intestinal microbiota composition in chickens of 245 days of age and different broiler lines, i.e., a high (HW) and low body weight (LW) line, the relative abundance of 48 microbial species was significantly different between sexes (Zhao et al., 2013). Furthermore, there was a significant interaction between genotype and sex. In HW lines, males and females had 30 species of bacteria that were different between them, and LW lines 17 species (Zhao et al., 2013).

In animal studies, often only males are used to create a stable baseline model that is not affected by cyclical reproductive hormone levels (Zucker and Beery, 2010 ). An interaction between probiotic treatment and sex for Bifidobacterium was found in 42-day-old broilers (Mountzouris et al., 2015). These results reinforce that the sex of a chicken might be a confounding factor. Many broiler and microbiota studies contain only data from males (Dumonceaux et al., 2006; Burkholder et al., 2008; Guardia et al., 2011; Hasan and Adem, 2011; La-Ongkhum et al., 2011; Stanley et al., 2012a; Akbarian et al., 2014; Goodarzi Boroojeni et al., 2014; Huff et al., 2015; Ruiz et al., 2015) or the sex of the broilers is unknown (Stanley et al., 2012b; Corrigan et al., 2015; Oakley and Kogut, 2016). This sex bias in literature might influence our understanding of the microbiota development in chickens and therefore the sex of the chicken should always be reported.

\section{Sampling the Gastrointestinal Tract of Chickens}

The gastrointestinal tract (GIT) regions consists of the crop, proventriculus, gizzard, duodenum, jejunum, ileum, caeca, large intestine and cloaca. The GIT regions have different functions that impact microbiota dynamics and should be considered when determining the sampling protocol and study design. Differences in composition and abundances of bacteria between the different GIT regions have been reviewed in detail previously (Yeoman et al., 2012; Stanley et al., 2014; Deusch et al., 2015). The different sections of the GIT have their own specific function in the digestion of feed, suggesting that there are differences in requirements for the types of microbiota that need to be present in each part. The crop primarily stores and pre-processes feed for further digestion (Richardson, 1970). For example, crop samples have been observed to show large differences in microbiota composition between individual broilers on the same diet (Sekelja et al., 2012; Choi et al., 2014). To illustrate, in one study with three individual 28-day-old broilers, the relative abundances of Firmicutes amounted to 95, 40, and 32\%, of Proteobacteria 5, 55, and 19\%, of Bacteroidetes 0, 3, and 36\%, and of Actinobacteria 0,2 , and $13 \%$ for the three broiler chickens (Choi et al., 2014). The large individual variation in this study may have been related to the time between feeding and sampling. This variable will be 
discussed in more detail in the section about feed access. The gizzard mechanically grinds feed and acts as a microbial barrier due to its low $\mathrm{pH}$ (Stanley et al., 2014), the duodenum receives digestive enzymes from the bile- and pancreatic ducts, and the main function of the ileum is the absorption of nutrients. Those three regions, however, are all dominated by Lactobacillus species (Konsak et al., 2013; Stanley et al., 2014).

The main function of the cecum is fermentation of nutrients (Clench and Mathias, 1995). From microbiota data of individual broilers it is known that there is more variability between individual ileum and cloaca samples than between ceca samples (Pissavin et al., 2012; Choi et al., 2014). The cecum is the part of the GIT with the highest microbial richness and is mainly colonized by anaerobic microorganisms (Salanitro et al., 1974; Videnska et al., 2013). The cecal microbiota is more diverse, has a greater richness, and is more stable compared with microbiota residing in the ileum (Gong et al., 2007; Owens et al., 2008; Stanley et al., 2014). In addition, an adequate sample size for a study depends on the type of samples as well. The high individual variation in crop samples compared to cecal samples will result in a lower number of cecal samples needed to find a potential difference.

Intestinal samples of chickens can only be acquired postmortem, and therefore, in many studies a less invasive method of sampling is preferred. Fecal samples and collection of cecal droppings have been used to determine intestinal microbiota composition. Cecal droppings reflect broilers' cecal microbiota, whereas fecal droppings do not (Pauwels et al., 2015; Stanley et al., 2015). Cecal droppings are difficult to collect because they are usually more easily trampled by the chickens and are produced less frequently than fecal droppings, with one cecal dropping for every seven to eight fecal droppings (Williams, 1995). Consequently, for comparisons between groups or studies, the location from which the intestinal samples originate should be taken into account to avoid misinterpretation of results.

\section{ENVIRONMENTAL FACTORS INFLUENCING INTESTINAL MICROBIOTA IN POULTRY}

\section{Biosecurity Level}

In poultry production, it has been suggested that compared to the situation where a chicken is hatched by the mother hen, the relatively high hygiene levels of hatcheries have an effect on the development of the GIT and immune system. It is suggested that this is due to a delayed exposure to a 'healthy' microbiota (Bailey, 2010), which is comparable to the 'hygiene hypothesis' postulated for humans (Lashner and Loftus, 2006). Moreover, the high hygiene levels within hatcheries may also result in variable intestinal microbiota between batches of newly hatched chickens. It has been hypothesized that their intestinal bacterial community is shaped rather randomly and is quite heterogeneous due to exposure to bacteria from a variety of environmental sources after hatch, rather than colonization by maternally derived bacteria (Stanley et al., 2013). These environmental sources include people handling the chicks, transport crates, the first feed and the litter in the poultry house. In broilers raised in isolators, it was shown that the intestinal morphology was altered with shorter villi, more shallow crypts and a reduced production of acidic mucin compared with conventionally raised broilers (Forder et al., 2007), which might result in a different microbiota composition. In studies with other animals, for example in pig studies it has been shown that the intestinal development in high hygiene environments, such as isolators, negatively impacts a normal succession of the intestinal microbiota because it influences the expression of large numbers of immune-related genes (Mulder et al., 2011), and reduces the microbiota diversity compared to piglet siblings raised on a farm (Inman et al., 2010).

\section{Housing}

Studies in humans have reported that individuals who live together show less variation of the intestinal microbiota compared to a group of random individuals (Yatsunenko et al., 2012; Schloss et al., 2014). In animal studies, a living-together effect, also referred to as a cage effect, is well-known, especially for animals that are coprophagic such as mice (McCafferty et al., 2013; Laukens et al., 2016). Since chickens are coprophagic as well, a cage effect is likely to occur in chicken studies. To avoid cage effects and to prevent uncontrolled intake of particles and feathers containing potentially influencing intestinal microbiota (Meyer et al., 2012), some researchers house the birds individually (Zhao et al., 2013; Org et al., 2015). Cage was also a factor in a study on C. perfringens, which showed that the variation in $C$. perfringens count tended to be smaller between birds from the same pen (Hofshagen and Kaldhusdal, 1992). Furthermore, as researchers recently proposed, different experimental units may differentially shape especially the non-dominant microbiota in broilers (Ludvigsen et al., 2016).

Also, the type of production system can influence microbiota composition. In a study comparing organic farms to conventional farms, a higher number of $C$. perfringens was found in ileum and caecum samples of broilers from organic farms (Bjerrum et al., 2006). In this case, the researchers suggested that this difference might be due to the antimicrobial drug salinomycin, applied as coccidiostat in the conventional feed, which has antibiotic properties that can affect the intestinal microbial composition (Bjerrum et al., 2006). Moreover, they found lower counts of Enterobacteriaceae and higher lactobacilli numbers in the ileal content of the birds raised on the organic farms (Bjerrum et al., 2006). Access to an outdoor range was demonstrated to enrich Bifidobacterium in ceca and ileum in Ross broilers (Gong et al., 2008), and resulted in a higher proportion of Bacteroidetes in the cecum and a lower Firmicutes/Bacteroidetes ratio in Dagu chickens (Xu et al., 2016). In the ceca of Dagu chickens housed in free-range systems, a higher abundance of bacteria associated with functions involved in amino acids and glycan metabolic pathways was observed (Xu et al., 2016). In the previous example, access to range may have altered the composition of the microbiota, but the timing of access to the range may be important as well. When access to range occurred during the last 4 weeks only, instead of from the 
beginning of the production period onward, no change in the richness of the broiler intestinal microbiota was found (Gong et al., 2008). Furthermore, the broiler density in a flock was also shown to affect the performance and the intestinal bacterial community (Beloor et al., 2010; Guardia et al., 2011). In a flock with a stocking density of 17 birds per $\mathrm{m}^{2}$ a decrease in growth performance and bacterial composition in the cecal samples was found, compared to a stocking density of 12 birds per $\mathrm{m}^{2}$ (Guardia et al., 2011). This effect was more pronounced in the first half of the broiler production period. However, whether this was a direct effect of the alterations in microbiota or due to other health and management problems associated with increased stocking densities remained unclear.

\section{Litter}

In poultry farming, litter is a mix of fecal and composted bedding material. Litter is an important environmental factor since chickens peck and forage in the litter. Litter is also used to collect samples to determine the intestinal composition of a flock. It has been demonstrated that the microbiota composition of litter samples collected from different production systems clustered with the corresponding microbiota composition of cecal samples (Mancabelli et al., 2016), suggesting that microbiota is exchanged between the chickens and the litter.

Depending on the litter type, litter quality and litter management the bacterial composition of chickens varies (Torok et al., 2009; Pan and Yu, 2014). It has been shown that litter type can affect the intestinal microbiota composition, for example birds raised on softwood sawdust vs. chopped straw showed significant differences in cecal microbial communities at 28 days of age (Torok et al., 2009). Also, it has been shown that female broilers grow slower on paper litter than on wood litter (Torok et al., 2011). This stresses the importance of the choice of litter material for microbiota studies, as it might affect interventions.

The quality of litter has, in several studies, been associated with the performance of the chickens (Welfare Quality, 2009; de Jong et al., 2014). Litter quality has been observed to vary also within the same poultry house, with for example, higher moisture content of litter underneath nipple drinkers (Dumas et al., 2011). Wet litter was found to have greater microbiota (alfa) diversity than dry litter, and this might influence the intestinal microbiota as well (Dumas et al., 2011; Oakley et al., 2013). Although in general litter samples of the same flock do not share many taxa with fecal samples, wet litter was more similar to fecal samples than dry litter (Oakley et al., 2013).

Reused litter may harbor pathogens from the previous flock (Stanley et al., 2004). In broilers reared on 7-day-old fresh litter the ileal microbiota was dominated by Lactobacillus spp., whereas in broilers reared on reused litter a group of unclassified Clostridiales were the dominating bacteria in the ileal microbiota (Cressman et al., 2010). In the litter the microbial (alpha) diversity between fresh litter and reused litter became similar at day 42 (Cressman et al., 2010). Another study showed that as litter aged, litter microbial diversity decreased (Pedroso et al., 2013), whereas the opposite tendency was observed for chicken intestinal microbiota.

\section{Feed Access}

After the first ingestion of feed after hatch a large increase in bacterial numbers in the chicken intestine can be observed (Shapiro and Sarles, 1949). Access to feed stimulates villus heightening and increased generation of cells in the crypt in young chicks (Gonzalez-Moran et al., 1985). In young chicks, delay in access to feed affects the development of the intestinal surface area (Uni et al., 1998; Lamot et al., 2014), and therefore potentially also the microbiota composition (Flint et al., 2012). Feed withdrawal later in life has also been associated with changes in microbiota composition (Burkholder et al., 2008; Vossen et al., 2009). Temporary feed withdrawal can result in an increased intestinal pathogen colonization (Thompson et al., 2008), for instance with Salmonella (Burkholder et al., 2008). After $6 \mathrm{~h}$ of feed deprivation, large changes in the bacterial community were observed in the proximal part of the GIT (Vossen et al., 2009). Daily cycles of light and darkness, feeding rhythm, or temperature affect eating behavior of animal hosts which creates a daily rhythm of the digestive system. As a consequently, many bacteria experience substantial environmental changes during the day, due to eating behavior of animal hosts, which is referred to as a bacterial circadian clock (Johnson et al., 2017). In a mouse study, cyclical changes in the intestinal microbiota from feeding/fasting rhythms added to the intra-individual variation (alfa diversity) of intestinal microbiota (Zarrinpar et al., 2014). Therefore, it is important that the time of feeding and/or feed deprivation and the moment of sampling are kept similar between birds or groups and are documented in scientific articles. Unfortunately, details on the duration of fasting before sampling are often not described.

\section{Climate and Geographical Location}

The local climate in a poultry house is an important factor that is well-known to influence the performance of chickens. The number of studies describing the effects of climate on microbiota, using 16S rRNA gene amplicon sequencing, are, however, limited. For heat stress, however, some studies are available that describe both the large effects on performance and alterations of the microbiota composition of broilers (Lan et al., 2004; Sohail et al., 2015). These alterations can lead to susceptibility to E. coli (Laudadio et al., 2012) and can contribute to increased intestinal colonization by Salmonella (Burkholder et al., 2008; Soliman et al., 2009). When birds experienced stress due to exposure to higher temperatures for $24 \mathrm{~h}$, greater changes were shown to occur in the ileal content compared to cecal samples, indicating that the microbiota in the ileum may be more sensitive to changes than the cecal microbiota (Burkholder et al., 2008).

The geographic location may affect the climate in the poultry house and as a consequence may influence the intestinal microbiota of chickens (Videnska et al., 2014a; Zhou et al., 2016). Although temperature in poultry houses is often controlled, broiler production may decrease because of the unfavorable influence of a hot environment (Laudadio et al., 2012). Especially when high ambient temperatures are combined with high relative humidity, chickens can experience heat stress. This may be the reason why in one flock in Austria in the years 2003-2006 and 2013 no seasonal effect was identified (Sofka et al., 2015). 
Recently, a between-sample (beta) diversity analysis did not show specific clustering based on the different geographical locations. However, effects of the geographical location were detectable when comparing species richness and intra-individual diversity (Siegerstetter et al., 2017). For many studies, geographical location and its effects on the climate the birds are exposed to are unknown. It is therefore often difficult to evaluate to what extent these factors may influence the research results.

\section{IMPLICATIONS OF CONFOUNDING FACTORS AFFECTING THE INTESTINAL MICROBIOTA IN CHICKENS}

The aim of this review was to provide an overview of host and environmental factors that affect the composition of the intestinal microbiota of poultry, to create awareness of confounding factors in poultry microbiota studies. We summarized the currently available knowledge regarding potential confounding factors separately, but of course, many of those factors cannot be seen independently. This review emphasizes the relevance of comprehensive documentation and reporting, as well as control of relevant host and environmental factors and molecular approaches in poultry microbiota studies, as previously suggested for studies with humans and mammals (Kilkenny et al., 2010; Laukens et al., 2016).

Of the factors that influence poultry microbiota composition (Figure 1), antibiotics and feed composition are wellknown for their effects on performance and the intestinal microbiota. Antibiotics and feed composition are often the main interventions that are the focus of a given study and were not discussed in this review, as our aim was to show which host and environmental factors that are not under investigation act as confounders, and may unintentionally have a large impact on the study outcome. For example, rather than the antibiotic treatment, a stronger effect on the composition of the microbiota was attributed to the environment in which chickens were raised, i.e., battery cages vs. floor pens (Pedroso et al., 2006). Furthermore, there are examples of studies that indicated an unexpected lack of differences in intestinal microbiota composition between diet interventions (Van Der Hoeven-Hangoor et al., 2013; Park et al., 2015), but did show clustering for different GIT regions, age groups and cages (Park et al., 2015; Ludvigsen et al., 2016). Consequently, not taking confounding factors properly into account with study design and data analysis might explain why antibiotics or a feed intervention does not show effects or an unrepeatable effect on the intestinal microbiota composition. Thus, host characteristics and environmental factors can have a large impact on conclusions that can be drawn from experiments and field studies.

Using knowledge of relevant confounding factors to improve study designs is an essential prerequisite to being able to generate data that will facilitate thorough understanding of the phylogeny and composition of the microbiota, and functionality of hostmicrobiota interactions. Although controlling for confounders is not always possible, detailed recording and reporting of these factors should be considered as an integral and essential part

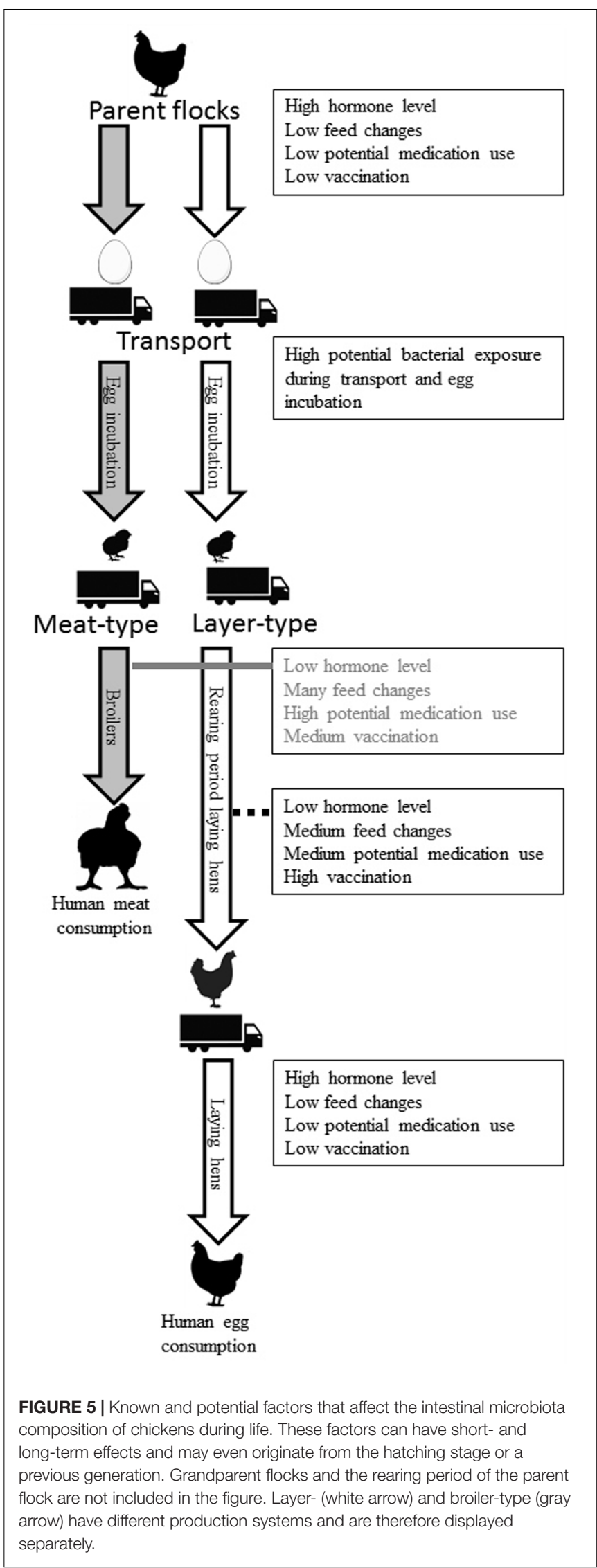


of each study. Providing details on study variables such as feed composition, feed access, feed changes, feed deprivation, medications (preventive and therapeutic), vaccines, age, sex, hygiene protocols, housing systems, litter type, flock density, housing temperature and location in the methodology part of publications, will improve the repeatability, the reproducibility, and the interpretation of chicken microbiota studies.

During the life of a chicken, many of the host and environmental factors discussed in this review can exert their respective effects on chickens. Figure 5 provides a compilation of known and potential effects on the intestinal microbiota composition of chickens, illustrating that many factors can have both short- and long-term effects and may even originate from the hatching stage or a previous generation. Layer-type and meat-type chickens have different production systems and are therefore displayed separately. The influences of hormonal changes due to the reproduction cycle are limited in broilers, due to their short lifespan, and also limited in the first part of the rearing period of layers. Near the end of the rearing period and the first part of the laying period, development of the reproductive organs and the start of egg production may affect GIT microbiota composition, as shown in mice (Org et al., 2016). Exposure to bacteria early in life, before, during and shortly after hatching, during transport or at the start of the rearing period (for layers) or production period (for broilers) has a potentially large impact on microbiota composition and immune development for both the short- and the long-term (Maynard et al., 2012). No or a delayed feed access, for example during transport to a farm, also can influence intestinal microbiota composition (Simon, 2016). Nevertheless, if this delayed feed access effect is biologically relevant in terms of stimulation and functionality of the immune system is still unclear. It is clear that perturbation of early life microbial colonization has long-term effects on immune development (Simon et al., 2016; Schokker et al., 2017).

The rearing period is associated with more feed changes, more preventive and therapeutic treatments and vaccinations than the laying period. In broilers, many feed changes, treatments, and vaccinations occur in a very short lifespan of approximately 6 weeks. It is known that different Salmonella vaccines used in broilers can change cecal microbiota composition (Park et al., 2017). This most likely also happens in the rearing period of laying hens. Since it is currently unknown how all those potential factors influence intestinal microbiota composition of chickens, further investigation is needed.

In Figures 2-4, 16S rRNA gene amplicon sequencing data was combined from different studies, although it should be noted that there is still limited 16S rRNA gene amplicon sequencing data available for one-day-old to 7-day-old broilers. In addition, the sample size of most studies is also limited, especially in the laying hen studies where the sample size is 3-6 birds. Another important observation that follows from these data is that in some studies, 30\% (Figure 2) to 20\% (Figure 3) of 16S rRNA multiplex amplification data has remained unclassified. To increase our biological understanding of host-microbe interactions these unknown microbes need to be identified. Consequently, there is still limited evidence that the colonization pattern of layer- and meat-types is different. Despite the limited availability of data and methodological differences between studies, it seems safe to conclude that layer- and meat-type chickens follow a different colonization pattern compared to mammals. For example, in human babies, a period has been identified were members of the phylum Actinobacteria are present in a high proportion (Reinhardt et al., 2009; De Filippo et al., 2010; Ottman et al., 2012; Schwartz et al., 2012). This period with a high proportion of Actinobacteria is neither observed in laying hens (Videnska et al., 2014b; Ballou et al., 2016; Polansky et al., 2016), nor in broilers (Figures 2, 3). In contrast with mammals that drink milk during the first weeks of life, chickens ingest solid feed from the day of hatch onward, which might explain the variation in colonization pattern between mammals and birds. Another possible explanation for the observed large differences between data of mammalian studies and poultry studies, is that in mammalian studies often fecal samples are used, whereas in chicken studies cecal samples are most often collected.

\section{CONCLUDING REMARKS}

Comprehensive analyses of intestinal microbiota will lead to better understanding of dynamics in microbial community structure and function, which will increase our understanding of intestinal health in poultry. Hence, research aimed at identifying biologically relevant characteristics of a healthy poultry microbiota, for instance as a foundation for nutritional and husbandry associated strategies to replace antimicrobial drugs, is both promising and challenging. It has been shown that microbiota studies have to deal with many hidden host and environmental variables, which are not all known. Therefore it is essential to be aware of the large impact the choice of study designs has on the results and thus on the interpretation of the outcomes of studies into the intestinal microbiota. Furthermore, providing details on study variables and sequence data repositories creates opportunities to combine data from different studies for meta-analysis, which will facilitate scientific breakthroughs toward innovative microbiota-inspired intervention strategies.

\section{AUTHOR CONTRIBUTIONS}

JK, FV, EF, JS, and HS initiated the project. JK searched the databases for potentially eligible articles based on their titles and abstracts and wrote the paper. FV, EF, GH, JS, and HS contributed to the development of the manuscript as a whole by giving constructive feedback on the manuscript during its preparation. All authors gave approval of the manuscript for publication.

\section{FUNDING}

This research was (partially) funded by NWO Earth and Life Sciences (ALW), with Project No. 868.15.020 and Cargill Animal Nutrition. 


\section{REFERENCES}

Akbarian, A., Kazerani, H. R., Mohri, M., Raji, A. R., Jamshidi, A., and Golian, A. (2014). Exogenous melatonin improves growth performance, intestinal microbiota, and morphology in temporarily feed restricted broilers. Livest. Sci. 167, 400-407. doi: 10.1016/j.livsci.2014.06.019

Allali, I., Arnold, J. W., Roach, J., Cadenas, M. B., Butz, N., Hassan, H. M., et al. (2017). A comparison of sequencing platforms and bioinformatics pipelines for compositional analysis of the gut microbiome. BMC Microbiol. 17:194. doi: 10.1186/s12866-017-1101-8

Antonissen, G., Eeckhaut, V., Van Driessche, K., Onrust, L., Haesebrouck, F., Ducatelle, R., et al. (2016). Microbial shifts associated with necrotic enteritis. Avian Pathol. 45, 308-312. doi: 10.1080/03079457.2016.1152625

Bailey, R. (2010). Intestinal Microbiota and the Pathogenesis of Dysbacteriosis in Broiler Chickens. Ph.D. thesis, University of East Anglia, Norwich.

Ballou, A. L., Ali, R. A., Mendoza, M. A., Ellis, J. C., Hassan, H. M., Croom, W. J., et al. (2016). Development of the chick microbiome: how early exposure influences future microbial diversity. Front. Vet. Sci. 3:2. doi: 10.3389/fvets. 2016.00002

Beloor, J., Kang, H. K., Kim, Y. J., Subramani, V. K., Jang, I. S., Sohn, S. H., et al. (2010). The effect of stocking density on stress related genes and telomeric length in broiler chickens. Asian Aust. J. Anim. Sci. 23, 437-443. doi: 10.5713/ ajas. 2010.90400

Benson, A. K., Kelly, S. A., Legge, R., Ma, F., Low, S. J., Kim, J., et al. (2010). Individuality in gut microbiota composition is a complex polygenic trait shaped by multiple environmental and host genetic factors. Proc. Natl. Acad. Sci. U.S.A. 107, 18933-18938. doi: 10.1073/pnas.1007028107

Bjerrum, L., Engberg, R. M., Leser, T. D., Jensen, B. B., Finster, K., and Pedersen, K. (2006). Microbial community composition of the ileum and cecum of broiler chickens as revealed by molecular and culture-based techniques. Poult. Sci. 85, 1151-1164. doi: 10.1093/ps/85.7.1151

Brisbin, J. T., Gong, J., and Sharif, S. (2008). Interactions between commensal bacteria and the gut-associated immune system of the chicken. Anim. Health Res. Rev. 9, 101-110. doi: 10.1017/s146625230800145x

Brooks, J. P., Edwards, D. J., Harwich, M. D. Jr., Rivera, M. C., Fettweis, J. M., Serrano, M. G., et al. (2015). The truth about metagenomics: quantifying and counteracting bias in 16S rRNA studies. BMC Microbiol. 15:66. doi: 10.1186/ s12866-015-0351-6

Burkholder, K. M., Thompson, K. L., Einstein, M. E., Applegate, T. J., and Patterson, J. A. (2008). Influence of stressors on normal intestinal microbiota, intestinal morphology, and susceptibility to Salmonella enteritidis colonization in broilers. Poult. Sci. 87, 1734-1741. doi: 10.3382/ps.200800107

Cason, J. A., Cox, N. A., and Bailey, J. S. (1994). Transmission of Salmnonella typhimurium during hatching of broiler chicks. Avian Dis. 38, 583-588. doi: $10.2307 / 1592082$

Cebra, J. J. (1999). Influences of microbiota on intestinal immune system development. Am. J. Clin. Nutr. 69, 1046S-1051S.

Choi, J. H., Kim, G. B., and Cha, C. J. (2014). Spatial heterogeneity and stability of bacterial community in the gastrointestinal tracts of broiler chickens. Poult. Sci. 93, 1942-1950. doi: 10.3382/ps.2014-03974

Clench, M. H., and Mathias, J. R. (1995). The avian cecum: a review. Wilson Bull. $107,93-121$

Corrigan, A., De Leeuw, M., Penaud-Frezet, S., Dimova, D., and Murphy, R. A. (2015). Phylogenetic and functional alterations in bacterial community compositions in broiler ceca as a result of mannan oligosaccharide supplementation. Appl. Environ. Microbiol. 81, 3460-3470. doi: 10.1128/aem. 04194- 14

Cressman, M. D., Yu, Z., Nelson, M. C., Moeller, S. J., Lilburn, M. S., and Zerby, H. N. (2010). Interrelations between the microbiotas in the litter and in the intestines of commercial broiler chickens. Appl. Environ. Microbiol. 76, 6572-6582. doi: 10.1128/aem.00180-10

Crhanova, M., Hradecka, H., Faldynova, M., Matulova, M., Havlickova, H., Sisak, F., et al. (2011). Immune response of chicken gut to natural colonization by gut microflora and to Salmonella enterica serovar enteritidis infection. Infect. Immun. 79, 2755-2763. doi: 10.1128/IAI.01375-10

Danzeisen, J. L., Kim, H. B., Isaacson, R. E., Tu, Z. J., and Johnson, T. J. (2011). Modulations of the chicken cecal microbiome and metagenome in response to anticoccidial and growth promoter treatment. PLoS One 6:e27949. doi: 10.1371/journal.pone.0027949

De Filippo, C., Cavalieri, D., Di Paola, M., Ramazzotti, M., Poullet, J. B., Massart, S., et al. (2010). Impact of diet in shaping gut microbiota revealed by a comparative study in children from Europe and rural Africa. Proc. Natl. Acad. Sci. U.S.A. 107, 14691-14696. doi: 10.1073/pnas.1005963107

de Jong, I. C., Gunnink, H., and Van Harn, J. (2014). Wet litter not only induces footpad dermatitis but also reduces overall welfare, technical performance, and carcass yield in broiler chickens. J. Appl. Poult. Res. 23, 51-58. doi: 10.3382/japr. 2013-00803

Deusch, S., Tilocca, B., Camarinha-Silva, A., and Seifert, J. (2015). News in livestock research - use of Omics-technologies to study the microbiota in the gastrointestinal tract of farm animals. Comput. Struct. Biotechnol. J. 13, 55-63. doi: 10.1016/j.csbj.2014.12.005

Donaldson, E. E., Stanley, D., Hughes, R. J., and Moore, R. J. (2017). The timecourse of broiler intestinal microbiota development after administration of cecal contents to incubating eggs. PeerJ 5:e3587. doi: 10.7717/peerj.3587

Dumas, M. D., Polson, S. W., Ritter, D., Ravel, J., Gelb, J Jr, Morgan, R., et al. (2011). Impacts of poultry house environment on poultry litter bacterial community composition. PLoS One 6:e24785. doi: 10.1371/journal.pone.002 4785

Dumonceaux, T. J., Hill, J. E., Hemmingsen, S. M., and Van Kessel, A. G. (2006). Characterization of intestinal microbiota and response to dietary virginiamycin supplementation in the broiler chicken. Appl. Environ. Microbiol. 72, 2815 2823. doi: 10.1128/aem.72.4.2815-2823.2006

Emam, M., Mehrabani-Yeganeh, H., Barjesteh, N., Nikbakht, G., ThompsonCrispi, K., Charkhkar, S., et al. (2014). The influence of genetic background versus commercial breeding programs on chicken immunocompetence. Poult. Sci. 93, 77-84. doi: 10.3382/ps.2013-03475

Flint, H. J., Scott, K. P., Louis, P., and Duncan, S. H. (2012). The role of the gut microbiota in nutrition and health. Nat. Rev. Gastroenterol. Hepatol. 9, 577-589. doi: $10.1038 /$ nrgastro.2012.156

Forder, R. E., Howarth, G. S., Tivey, D. R., and Hughes, R. J. (2007). Bacterial modulation of small intestinal goblet cells and mucin composition during early posthatch development of poultry. Poult. Sci. 86, 2396-2403. doi: 10.3382/ps. 2007-00222

Gantois, I., Ducatelle, R., Pasmans, F., Haesebrouck, F., Gast, R., Humphrey, T. J., et al. (2009). Mechanisms of egg contamination by Salmonella enteritidis. FEMS Microbiol. Rev. 33, 718-738. doi: 10.1111/j.1574-6976.2008. 00161.x

Gerard, P., Brezillon, C., Quere, F., Salmon, A., and Rabot, S. (2008) Characterization of cecal microbiota and response to an orally administered lactobacillus probiotic strain in the broiler chicken. J. Mol. Microbiol. Biotechnol. 14, 115-122. doi: 10.1159/000106090

Gong, J., Si, W., Forster, R. J., Huang, R., Yu, H., Yin, Y., et al. (2007). 16S rRNA gene-based analysis of mucosa-associated bacterial community and phylogeny in the chicken gastrointestinal tracts: from crops to ceca. FEMS Microbiol. Ecol. 59, 147-157. doi: 10.1111/j.1574-6941.2006.00193.x

Gong, J., Yu, H., Liu, T., Gill, J. J., Chambers, J. R., Wheatcroft, R., et al. (2008). Effects of zinc bacitracin, bird age and access to range on bacterial microbiota in the ileum and caeca of broiler chickens. J. Appl. Microbiol. 104, 1372-1382. doi: 10.1111/j.1365-2672.2007.03699.x

Gonzalez-Moran, G., Gonzalez-Del Pliego, M., and Pedernera, E. (1985). Morphological changes in the ovary of newly hatched chickens treated with chorionic gonadotropin during embryonic development. Gen. Comp. Endocrinol. 59, 162-167. doi: 10.1016/0016-6480(85)90431-9

Goodarzi Boroojeni, F., Vahjen, W., Mader, A., Knorr, F., Ruhnke, I., Rohe, I., et al. (2014). The effects of different thermal treatments and organic acid levels in feed on microbial composition and activity in gastrointestinal tract of broilers. Poult. Sci. 93, 1440-1452. doi: 10.3382/ps.2013-03763

Grindstaff, J. L., Brodie, E. D. III, and Ketterson, E. D. (2003). Immune function across generations: integrating mechanism and evolutionary process in maternal antibody transmission. Proc. Biol. Sci. 270, 2309-2319. doi: 10.1098/ rspb.2003.2485

Guardia, S., Konsak, B., Combes, S., Levenez, F., Cauquil, L., Guillot, J. F., et al (2011). Effects of stocking density on the growth performance and digestive microbiota of broiler chickens. Poult. Sci. 90, 1878-1889. doi: 10.3382/ps.201001311 
Hamal, K. R., Burgess, S. C., Pevzner, I. Y., and Erf, G. F. (2006). Maternal antibody transfer from dams to their egg yolks, egg whites, and chicks in meat lines of chickens. Poul. Sci. 85, 1364-1372. doi: 10.1093/ps/85.8.1364

Han, G. G., Kim, E. B., Lee, J., Lee, J. Y., Jin, G., Park, J., et al. (2016a). Relationship between the microbiota in different sections of the gastrointestinal tract, and the body weight of broiler chickens. Springerplus 5:911. doi: 10.1186/s40064016-2604-8

Han, Z., Pielsticker, C., Gerzova, L., Rychlik, I., and Rautenschlein, S. (2016c). The influence of age on Campylobacter jejuni infection in chicken. Dev. Comp. Immunol. 62, 58-71. doi: 10.1016/j.dci.2016.04.020

Han, Z., Willer, T., Pielsticker, C., Gerzova, L., Rychlik, I., and Rautenschlein, S. (2016b). Differences in host breed and diet influence colonization by Campylobacter jejuni and induction of local immune responses in chicken. Gut Pathog. 8:56. doi: 10.1186/s13099-016-0133-1

Hasan, A., and Adem, Y. (2011). Influence of dietary thymol and carvacrol preparation and/or an organic acid blend on growth performance, digestive organs and intestinal microbiota of broiler chickens. Afr. J. Microbiol. Res. 5, 979-984. doi: 10.5897/ajmr10.203

Hermes, G. D., Zoetendal, E. G., and Smidt, H. (2015). Molecular ecological tools to decipher the role of our microbial mass in obesity. Benef. Microbes 6, 61-81. doi: 10.3920/BM2014.0016

Hofshagen, M., and Kaldhusdal, M. (1992). Barley inclusion and avoparcin supplementation in broiler diets. 1. Effect on small intestinal bacterial flora and performance. Poult. Sci. 71, 959-969. doi: 10.3382/ps.0710959

Hook, D., Jalaludin, B., and Fitzsimmons, G. (1996). Clostridium perfringens foodborne outbreak: an epidemiological investigation. Aust. N. Z. J. Public Health 20, 119-122. doi: 10.1111/j.1753-6405.1996.tb01804.x

Huff, G. R., Huff, W. E., Rath, N. C., El-Gohary, F. A., Zhou, Z. Y., and Shini, S. (2015). Efficacy of a novel prebiotic and a commercial probiotic in reducing mortality and production losses due to cold stress and Escherichia coli challenge of broiler chicks 1. Poult. Sci. 94, 918-926. doi: 10.3382/ps/pev068

Inman, C. F., Haverson, K., Konstantinov, S. R., Jones, P. H., Harris, C., Smidt, H., et al. (2010). Rearing environment affects development of the immune system in neonates. Clin. Exp. Immunol. 160, 431-439. doi: 10.1111/j.1365-2249.2010. 04090.x

Jang, S. I., Lillehoj, H. S., Lee, S. H., Lee, K. W., Lillehoj, E. P., Hong, Y. H., et al. (2013). Relative disease susceptibility and clostridial toxin antibody responses in three commercial broiler lines coinfected with Clostridium perfringens and Eimeria maxima using an experimental model of necrotic enteritis. Avian Dis. 57, 684-687. doi: 10.1637/10496-011813-ResNote.1

Johnson, C. H., Zhao, C., Xu, Y., and Mori, T. (2017). Timing the day: what makes bacterial clocks tick? Nat. Rev. Microbiol. 15, 232-242. doi: 10.1038/nrmicro. 2016.196

Kilkenny, C., Browne, W. J., Cuthill, I. C., Emerson, M., and Altman, D. G. (2010). Improving bioscience research reporting: the ARRIVE guidelines for reporting animal research. PLoS Biol. 8:e1000412. doi: 10.1371/journal.pbio.1000412

Kim, J. E., Lillehoj, H. S., Hong, Y. H., Kim, G. B., Lee, S. H., Lillehoj, E. P., et al. (2015). Dietary Capsicum and Curcuma longa oleoresins increase intestinal microbiome and necrotic enteritis in three commercial broiler breeds. Res. Vet. Sci. 102, 150-158. doi: 10.1016/j.rvsc.2015.07.022

Kohl, K. D. (2012). Diversity and function of the avian gut microbiota. J. Comp. Physiol. B 182, 591-602. doi: 10.1007/s00360-012-0645-z

Konsak, B. M., Stanley, D., Haring, V. R., Geier, M. S., Hughes, R. J., Howarth, G. S., et al. (2013). Identification of differential duodenal gene expression levels and microbiota abundance correlated with differences in energy utilisation in chickens. Anim. Prod. Sci. 53, 1269-1275. doi: 10.1071/AN12426

Lamot, D. M., Van De Linde, I. B., Molenaar, R., Van Der Pol, C. W., Wijtten, P. J., Kemp, B., et al. (2014). Effects of moment of hatch and feed access on chicken development. Poult. Sci. 93, 2604-2614. doi: 10.3382/ps.2014-04123

Lan, P. T. N., Sakamoto, M., and Benno, Y. (2004). Effects of two probiotic Lactobacillus strains on jejunal and cecal microbiota of broiler chicken under acute heat stress condition as revealed by molecular analysis of $16 \mathrm{~S}$ rRNA genes. Microbiol. Immunol. 48, 917-929. doi: 10.1111/j.1348-0421.2004.tb0 3620.x

La-Ongkhum, O., Pungsungvorn, N., Amornthewaphat, N., and Nitisinprasert, S. (2011). Effect of the antibiotic avilamycin on the structure of the microbial community in the jejunal intestinal tract of broiler chickens. Poult. Sci. 90, 1532-1538. doi: 10.3382/ps.2010-01288
Lashner, B. A., and Loftus, E. V. Jr. (2006). True or false? The hygiene hypothesis for Crohn's disease. Am. J. Gastroenterol. 101, 1003-1004. doi: 10.1111/j.15720241.2006.00563.x

Laudadio, V., Dambrosio, A., Normanno, G., Khan, R. U., Naz, S., Rowghani, E., et al. (2012). Effect of reducing dietary protein level on performance responses and some microbiological aspects of broiler chickens under summer environmental conditions. Avian Biol. Res. 5, 88-92. doi: 10.3184/ 175815512 X13350180713553

Laukens, D., Brinkman, B. M., Raes, J., De Vos, M., and Vandenabeele, P. (2016). Heterogeneity of the gut microbiome in mice: guidelines for optimizing experimental design. FEMS Microbiol. Rev. 40, 117-132. doi: 10.1093/femsre/ fuv036

Li, Y., Xu, Q., Huang, Z., Lv, L., Liu, X., Yin, C., et al. (2016). Effect of Bacillus subtilis CGMCC 1.1086 on the growth performance and intestinal microbiota of broilers. J. Appl. Microbiol. 120, 195-204. doi: 10.1111/jam.12972

Lim, S., Cho, S., Caetano-Anolles, K., Jeong, S. G., Oh, M. H., Park, B. Y., et al. (2015). Developmental dynamic analysis of the excreted microbiome of chickens using next-generation sequencing. J. Mol. Microbiol. Biotechnol. 25, 262-268. doi: 10.1159/000430865

Lin, Y., Xu, S., Zeng, D., Ni, X., Zhou, M., Zeng, Y., et al. (2017). Disruption in the cecal microbiota of chickens challenged with Clostridium perfringens and other factors was alleviated by Bacillus licheniformis supplementation. PLoS One 12:e0182426. doi: 10.1371/journal.pone.0182426

Lozupone, C. A., Stombaugh, J., Gonzalez, A., Ackermann, G., Wendel, D., Vazquez-Baeza, Y., et al. (2013). Meta-analyses of studies of the human microbiota. Genome Res. 23, 1704-1714. doi: 10.1101/gr.151803.112

Ludvigsen, J., Svihus, B., and Rudi, K. (2016). Rearing room affects the non-dominant chicken cecum microbiota, while diet affects the dominant microbiota. Front. Vet. Sci. 3:16. doi: 10.3389/fvets.2016.00016

Lumpkins, B. S., Batal, A. B., and Lee, M. (2008). The effect of gender on the bacterial community in the gastrointestinal tract of broilers. Poult. Sci. 87, 964-967. doi: 10.3382/ps.2007-00287

Mancabelli, L., Ferrario, C., Milani, C., Mangifesta, M., Turroni, F., Duranti, S., et al. (2016). Insights into the biodiversity of the gut microbiota of broiler chickens. Environ. Microbiol. 18, 4727-4738. doi: 10.1111/1462-2920. 13363

Maynard, C. L., Elson, C. O., Hatton, R. D., and Weaver, C. T. (2012). Reciprocal interactions of the intestinal microbiota and immune system. Nature 489, 231-241. doi: 10.1038/nature11551

McCafferty, J., Muhlbauer, M., Gharaibeh, R. Z., Arthur, J. C., Perez-Chanona, E., Sha, W., et al. (2013). Stochastic changes over time and not founder effects drive cage effects in microbial community assembly in a mouse model. ISME J. 7, 2116-2125. doi: 10.1038/ismej.2013.106

Meng, H., Zhang, Y., Zhao, L., Zhao, W., He, C., Honaker, C. F., et al. (2014). Body weight selection affects quantitative genetic correlated responses in gut microbiota. PLoS One 9:e89862. doi: 10.1371/journal.pone.0089862

Meyer, B., Bessei, W., Vahjen, W., Zentek, J., and Harlander-Matauschek, A. (2012). Dietary inclusion of feathers affects intestinal microbiota and microbial metabolites in growing Leghorn-type chickens. Poult. Sci. 91, 1506-1513. doi: 10.3382/ps.2011-01786

Mignon-Grasteau, S., Narcy, A., Rideau, N., Chantry-Darmon, C., Boscher, M. Y., Sellier, N., et al. (2015). Impact of selection for digestive efficiency on microbiota composition in the chicken. PLoS One 10:e0135488. doi: 10.1371/journal.pone. 0135488

Mohd Shaufi, M. A., Sieo, C. C., Chong, C. W., Gan, H. M., and Ho, Y. W. (2015). Deciphering chicken gut microbial dynamics based on high-throughput 16S rRNA metagenomics analyses. Gut Pathog. 7:4. doi: 10.1186/s13099-0150051-7

Moore, R. J. (2016). Necrotic enteritis predisposing factors in broiler chickens. Avian Pathol. 45, 275-281. doi: 10.1080/03079457.2016.1150587

Mountzouris, K. C., Palamidi, I., Tsirtsikos, P., Mohnl, M., Schatzmayr, G., and Fegeros, K. (2015). Effect of dietary inclusion level of a multi-species probiotic on broiler performance and two biomarkers of their caecal ecology. Anim. Prod. Sci. 55, 484-493. doi: 10.1071/AN13358

Mulder, I. E., Schmidt, B., Lewis, M., Delday, M., Stokes, C. R., Bailey, M., et al. (2011). Restricting microbial exposure in early life negates the immune benefits associated with gut colonization in environments of high microbial diversity. PLoS One 6:e28279. doi: 10.1371/journal.pone.0028279 
Nakphaichit, M., Thanomwongwattana, S., Phraephaisarn, C., Sakamoto, N., Keawsompong, S., Nakayama, J., et al. (2011). The effect of including Lactobacillus reuteri KUB-AC5 during post-hatch feeding on the growth and ileum microbiota of broiler chickens. Poult. Sci. 90, 2753-2765. doi: 10.3382/ps. 2011-01637

Nava, G. M., Bielke, L. R., Callaway, T. R., and Castañeda, M. P. (2007). Probiotic alternatives to reduce gastrointestinal infections: the poultry experience. Anim. Health Res. Rev. 6, 105-118. doi: 10.1079/ahr2005103

Oakley, B. B., and Kogut, M. H. (2016). Spatial and temporal changes in the broiler chicken cecal and fecal microbiomes and correlations of bacterial taxa with cytokine gene expression. Front. Vet. Sci. 3:11. doi: 10.3389/fvets.2016.00011

Oakley, B. B., Morales, C. A., Line, J., Berrang, M. E., Meinersmann, R. J., Tillman, G. E., et al. (2013). The poultry-associated microbiome: network analysis and farm-to-fork characterizations. PLoS One 8:e57190. doi: 10.1371/journal.pone. 0057190

Org, E., Mehrabian, M., Parks, B. W., Shipkova, P., Liu, X., Drake, T. A., et al. (2016). Sex differences and hormonal effects on gut microbiota composition in mice. Gut Microbes 7, 313-322. doi: 10.1080/19490976.2016.1203502

Org, E., Parks, B. W., Joo, J. W., Emert, B., Schwartzman, W., Kang, E. Y., et al. (2015). Genetic and environmental control of host-gut microbiota interactions. Genome Res. 25, 1558-1569. doi: 10.1101/gr.194118.115

Ottman, N., Smidt, H., De Vos, W. M., and Belzer, C. (2012). The function of our microbiota: who is out there and what do they do? Front. Cell. Infect. Microbiol. 2:104. doi: $10.3389 /$ fcimb.2012.00104

Owens, B., Tucker, L., Collins, M. A., and Mccracken, K. J. (2008). Effects of different feed additives alone or in combination on broiler performance, gut microflora and ileal histology. Br. Poult. Sci. 49, 202-212. doi: 10.1080/ 00071660802004890

Pan, D., and Yu, Z. (2014). Intestinal microbiome of poultry and its interaction with host and diet. Gut Microbes 5, 108-119. doi: 10.4161/gmic.26945

Park, S. H., Dowd, S. E., Mcreynolds, J. L., Byrd, J. A., Nisbet, D. J., and Ricke, S. C. (2015). Evaluation of feed grade sodium bisulfate impact on gastrointestinal tract microbiota ecology in broilers via a pyrosequencing platform. Poult. Sci. 94, 3040-3047. doi: 10.3382/ps/pev274

Park, S. H., Kim, S. A., Rubinelli, P. M., Roto, S. M., and Ricke, S. C. (2017). Microbial compositional changes in broiler chicken cecal contents from birds challenged with different Salmonella vaccine candidate strains. Vaccine 35, 3204-3208. doi: 10.1016/j.vaccine.2017.04.073

Pauwels, J., Taminiau, B., Janssens, G. P., De Beenhouwer, M., Delhalle, L., Daube, G., et al. (2015). Cecal drop reflects the chickens' cecal microbiome, fecal drop does not. J. Microbiol. Methods 117, 164-170. doi: 10.1016/j.mimet.2015. 08.006

Pedroso, A. A., Batal, A. B., and Lee, M. D. (2016). Effect of in ovo administration of an adult-derived microbiota on establishment of the intestinal microbiome in chickens. Am. J. Vet. Res. 77, 514-526. doi: 10.2460/ajvr.77.5.514

Pedroso, A. A., Hurley-Bacon, A. L., Zedek, A. S., Kwan, T. W., Jordan, A. P., Avellaneda, G., et al. (2013). Can probiotics improve the environmental microbiome and resistome of commercial poultry production? Int. J. Environ. Res. Public Health 10, 4534-4559. doi: 10.3390/ijerph10104534

Pedroso, A. A., Menten, J. F., Lambais, M. R., Racanicci, A. M., Longo, F. A., and Sorbara, J. O. (2006). Intestinal bacterial community and growth performance of chickens fed diets containing antibiotics. Poult. Sci. 85, 747-752. doi: 10.1093/ ps/85.4.747

Pedroso, A. A., Menten, J. F. M., and Lambais, M. R. (2005). The structure of bacterial community in the intestines of newly hatched chicks1. J. Appl. Poul. Res. 14, 232-237. doi: 10.1093/japr/14.2.232

Persoons, D., Haesebrouck, F., Smet, A., Herman, L., Heyndrickx, M., Martel, A., et al. (2011). Risk factors for ceftiofur resistance in Escherichia coli from Belgian broilers. Epidemiol. Infect. 139, 765-771. doi: 10.1017/S09502688100 01524

Pissavin, C., Burel, C., Gabriel, I., Beven, V., Mallet, S., Maurice, R., et al. (2012). Capillary electrophoresis single-strand conformation polymorphism for the monitoring of gastrointestinal microbiota of chicken flocks. Poult. Sci. 91, 2294-2304. doi: 10.3382/ps.2011-01911

Polansky, O., Sekelova, Z., Faldynova, M., Sebkova, A., Sisak, F., and Rychlik, I. (2016). Important metabolic pathways and biological processes expressed by chicken cecal microbiota. Appl. Environ. Microbiol. 82, 1569-1576. doi: 10.1128/ AEM.03473-15
Pourabedin, M., Guan, L., and Zhao, X. (2015). Xylo-oligosaccharides and virginiamycin differentially modulate gut microbial composition in chickens. Microbiome 3:15. doi: 10.1186/s40168-015-0079-4

Qu, A., Brulc, J. M., Wilson, M. K., Law, B. F., Theoret, J. R., Joens, L. A., et al. (2008). Comparative metagenomics reveals host specific metavirulomes and horizontal gene transfer elements in the chicken cecum microbiome. PLoS One 3:e2945. doi: 10.1371/journal.pone.0002945

Reardon, S. (2016). A mouse's house may ruin studies. Nature 530, 264-264. doi: 10.1038/nature.2016.19335

Reinhardt, C., Reigstad, C. S., and Backhed, F. (2009). Intestinal microbiota during infancy and its implications for obesity. J. Pediatr. Gastroenterol. Nutr. 48, 249-256. doi: 10.1097/MPG.0b013e318183187c

Richardson, A. J. (1970). The role of the crop in the feeding behaviour of the domestic chicken. Anim. Behav. 18, 633-639. doi: 10.1016/0003-3472(70) 90006-0

Roto, S. M., Kwon, Y. M., and Ricke, S. C. (2016). Applications of in ovo technique for the optimal development of the gastrointestinal tract and the potential influence on the establishment of its microbiome in poultry. Front. Vet. Sci. 3:63. doi: $10.3389 /$ fvets. 2016.00063

Ruiz, R., Barroso-Deljesus, A., Lara, L., and Rubio, L. A. (2015). The use of multiple restriction enzymes in terminal restriction fragment length polymorphism analysis and identification of performance-related caecal bacterial groups in growing broiler chickens. J. Agric. Sci. 153, 1491-1505. doi: 10.1017/ S0021859615000611

Salanitro, J. P., Blake, I. G., and Muirhead, P. A. (1974). Studies on the cecal microflora of commercial broiler chickens. Appl. Microbiol. 28, 439-447.

Schloss, P. D., Iverson, K. D., Petrosino, J. F., and Schloss, S. J. (2014). The dynamics of a family's gut microbiota reveal variations on a theme. Microbiome 2:25. doi: 10.1186/2049-2618-2-25

Schokker, D., Jansman, A. J., Veninga, G., De Bruin, N., Vastenhouw, S. A., De Bree, F. M., et al. (2017). Perturbation of microbiota in one-day old broiler chickens with antibiotic for 24 hours negatively affects intestinal immune development. BMC Genomics 18:241. doi: 10.1186/s12864-017-3625-6

Schokker, D., Veninga, G., Vastenhouw, S. A., Bossers, A., De Bree, F. M., KaalLansbergen, L. M., et al. (2015). Early life microbial colonization of the gut and intestinal development differ between genetically divergent broiler lines. BMC Genomics 16:418. doi: 10.1186/s12864-015-1646-6

Schwartz, S., Friedberg, I., Ivanov, I. V., Davidson, L. A., Goldsby, J. S., Dahl, D. B., et al. (2012). A metagenomic study of diet-dependent interaction between gut microbiota and host in infants reveals differences in immune response. Genome Biol. 13:r32. doi: 10.1186/gb-2012-13-4-r32

Sekelja, M., Rud, I., Knutsen, S. H., Denstadli, V., Westereng, B., Naes, T., et al. (2012). Abrupt temporal fluctuations in the chicken fecal microbiota are explained by its gastrointestinal origin. Appl. Environ. Microbiol. 78, 2941-2948. doi: 10.1128/aem.05391-11

Sergeant, M. J., Constantinidou, C., Cogan, T. A., Bedford, M. R., Penn, C. W., and Pallen, M. J. (2014). Extensive microbial and functional diversity within the chicken cecal microbiome. PLoS One 9:e91941. doi: 10.1371/journal.pone. 0091941

Shapiro, S. K., Rhodes, R. A., and Sarles, W. B. (1949). Lactobacilli in the intestinal tract of the chicken. J. Bacteriol. 58, 689-694.

Shapiro, S. K., and Sarles, W. B. (1949). Microorganisms in the intestinal tract of normal chickens. J. Bacteriol. 58, 531-544.

Siegerstetter, S. C., Schmitz-Esser, S., Magowan, E., Wetzels, S. U., Zebeli, Q. Lawlor, P. G., et al. (2017). Intestinal microbiota profiles associated with low and high residual feed intake in chickens across two geographical locations. PLoS One 12:e187766. doi: 10.1371/journal.pone.0187766

Simon, K. (2016). Effects of Early Life Conditions on Immunity in Broilers and Layers. Ph.D. thesis, Wageningen University, Wageningen, NL.

Simon, K., De Vries Reilingh, G., Kemp, B., and Lammers, A. (2014). Development of ileal cytokine and immunoglobulin expression levels in response to early feeding in broilers and layers. Poult. Sci. 93, 3017-3027. doi: 10.3382/ps.201404225

Simon, K., Verwoolde, M. B., Zhang, J., Smidt, H., De Vries Reilingh, G., Kemp, B., et al. (2016). Long-term effects of early life microbiota disturbance on adaptive immunity in laying hens. Poult. Sci. 95, 1543-1554. doi: 10.3382/ps/pew088

Singh, K. M., Shah, T. M., Reddy, B., Deshpande, S., Rank, D. N., and Joshi, C. G. (2014). Taxonomic and gene-centric metagenomics of the fecal microbiome of 
low and high feed conversion ratio (FCR) broilers. J. Appl. Genet. 55, 145-154. doi: 10.1007/s13353-013-0179-4

Singh, P., Karimi, A., Devendra, K., Waldroup, P. W., Cho, K. K., and Kwon, Y. M. (2013). Influence of penicillin on microbial diversity of the cecal microbiota in broiler chickens. Poult. Sci. 92, 272-276. doi: 10.3382/ps.2012-02603

Sofka, D., Pfeifer, A., Gleiss, B., Paulsen, P., and Hilbert, F. (2015). Changes within the intestinal flora of broilers by colonisation with Campylobacter jejuni. Berl. Münch. Tierärztl. Wochenschr. 128, 104-110.

Sohail, M. U., Hume, M. E., Byrd, J. A., Nisbet, D. J., Shabbir, M. Z., Ijaz, A., et al. (2015). Molecular analysis of the caecal and tracheal microbiome of heatstressed broilers supplemented with prebiotic and probiotic. Avian Pathol. 44, 67-74. doi: 10.1080/03079457.2015.1004622

Soliman, E. S., Taha, E., Infante, K. D., Laboy, K., Sobieh, M. A., and Reddy, P. G. (2009). Stressors influence on Salmonella enterica serovar enteritidis colonization in broilers. Am. J. Anim. Vet. Sci. 4, 42-48. doi: 10.3382/ps.200800107

Stanley, D., Denman, S. E., Hughes, R. J., Geier, M. S., Crowley, T. M., Chen, H., et al. (2012a). Intestinal microbiota associated with differential feed conversion efficiency in chickens. Appl. Microbiol. Biotechnol. 96, 1361-1369. doi: 10.1007/ s00253-011-3847-5

Stanley, D., Geier, M. S., Chen, H., Hughes, R. J., and Moore, R. J. (2015). Comparison of fecal and cecal microbiotas reveals qualitative similarities but quantitative differences. BMC Microbiol. 15:51. doi: 10.1186/s12866-0150388-6

Stanley, D., Geier, M. S., Hughes, R. J., Denman, S. E., and Moore, R. J. (2013). Highly variable microbiota development in the chicken gastrointestinal tract. PLoS One 8:e84290. doi: 10.1371/journal.pone.0084290

Stanley, D., Hughes, R. J., and Moore, R. J. (2014). Microbiota of the chicken gastrointestinal tract: influence on health, productivity and disease. Appl. Microbiol. Biotechnol. 98, 4301-4310. doi: 10.1007/s00253-014-5646-2

Stanley, D., Keyburn, A. L., Denman, S. E., and Moore, R. J. (2012b). Changes in the caecal microflora of chickens following Clostridium perfringens challenge to induce necrotic enteritis. Vet. Microbiol. 159, 155-162. doi: 10.1016/j.vetmic. 2012.03.032

Stanley, V. G., Gray, C., Daley, M., Krueger, W. F., and Sefton, A. E. (2004). An alternative to antibiotic-based drugs in feed for enhancing performance of broilers grown on Eimeria spp.-infected litter. Poult. Sci. 83, 39-44. doi: $10.1093 / \mathrm{ps} / 83.1 .39$

Thibodeau, A., Letellier, A., Yergeau, E., Larriviere-Gauthier, G., and Fravalo, P. (2017). Lack of evidence that selenium-yeast improves chicken health and modulates the caecal microbiota in the context of colonization by Campylobacter jejuni. Front. Microbiol. 8:451. doi: 10.3389/fmicb.2017.00451

Thompson, K., Burkholder, K., Patterson, J., and Applegate, T. J. (2008). Microbial ecology shifts in the ileum of broilers during feed withdrawal and dietary manipulations. Poult. Sci. 87, 1624-1632. doi: 10.3382/ps.2007-00324

Torok, V. A., Dyson, C., Mckay, A., and Ophel-Keller, K. (2013). Quantitative molecular assays for evaluating changes in broiler gut microbiota linked with diet and performance. Anim. Prod. Sci. 53, 1260-1268. doi: 10.1071/AN12272

Torok, V. A., Hughes, R. J., Mikkelsen, L. L., Perez-Maldonado, R., Balding, K., Macalpine, R., et al. (2011). Identification and characterization of potential performance-related gut microbiotas in broiler chickens across various feeding trials. Appl. Environ. Microbiol. 77, 5868-5878. doi: 10.1128/aem.00165-11

Torok, V. A., Hughes, R. J., Ophel-Keller, K., Ali, M., and Macalpine, R. (2009). Influence of different litter materials on cecal microbiota colonization in broiler chickens. Poult. Sci. 88, 2474-2481. doi: 10.3382/ps.2008-00381

Uni, Z., Ganot, S., and Sklan, D. (1998). Posthatch development of mucosal function in the broiler small intestine. Poult. Sci. 77, 75-82. doi: 10.1093/ps/ 77.1 .75

Uni, Z., Noy, Y., and Sklan, D. (1996). Development of the small intestine in heavy and light strain chicks before and after hatching. Br. Poult. Sci. 37, 63-71. doi: $10.1080 / 00071669608417837$

Van Der Hoeven-Hangoor, E., Van Der Vossen, J. M., Schuren, F. H., Verstegen, M. W., De Oliveira, J. E., Montijn, R. C., et al. (2013). Ileal microbiota composition of broilers fed various commercial diet compositions. Poult. Sci. 92, 2713-2723. doi: 10.3382/ps.2013-03017

Van Immerseel, F., De Buck, J., Pasmans, F., Huyghebaert, G., Haesebrouck, F., and Ducatelle, R. (2004). Clostridium perfringens in poultry: an emerging threat for animal and public health. Avian Pathol. 33, 537-549. doi: 10.1080/ 03079450400013162
Videnska, P., Faldynova, M., Juricova, H., Babak, V., Sisak, F., Havlickova, H., et al. (2013). Chicken faecal microbiota and disturbances induced by single or repeated therapy with tetracycline and streptomycin. BMC Vet. Res. 9:30. doi: 10.1186/1746-6148-9-30

Videnska, P., Rahman, M. M., Faldynova, M., Babak, V., Matulova, M. E., PruknerRadovcic, E., et al. (2014a). Characterization of egg laying hen and broiler fecal microbiota in poultry farms in Croatia, Czech Republic, Hungary and Slovenia. PLoS One 9:e110076. doi: 10.1371/journal.pone.0110076

Videnska, P., Sedlar, K., Lukac, M., Faldynova, M., Gerzova, L., Cejkova, D., et al. (2014b). Succession and replacement of bacterial populations in the caecum of egg laying hens over their whole life. PLoS One 9:e115142. doi: 10.1371/journal. pone. 0115142

Vossen, J. M. B. M., Hangoor, E., Oliveira, J. E. D., Ouwens, A. M. T., Scott, T., Montijn, R. C., et al. (2009). "Metagenomic analysis reveals the dynamics of gut microbiome in different compartments of the chicken gut upon feeding," in Proceedings of the Abstract Retrieved from NuGO Annual conference 2009, 6th Edn, Conshohocken, PA.

Waite, D. W., and Taylor, M. W. (2014). Characterizing the avian gut microbiota: membership, driving influences, and potential function. Front. Microbiol. 5:223. doi: $10.3389 /$ fmicb. 2014.00223

Welfare Quality (2009). Welfare Quality Assessment Protocol for Poultry (Broilers, Laying Hens). Lelystad: Welfare Quality Consortium.

Williams, R. B. (1995). Epidemiological studies of coccidiosis in the domesticated fowl (Gallus gallus):III. The influence of the fowl's defaecation pattern on the excretion patterns of Eimeria tenella and E acervulina oocysts. Appl. Parasitol. $36,279-289$.

Williams, S. C. (2014). Gnotobiotics. Proc. Natl. Acad. Sci. U.S.A. 111, 1661. doi: $10.1073 /$ pnas.1324049111

Witzig, M., Camarinha-Silva, A., Green-Engert, R., Hoelzle, K., Zeller, E., Seifert, J., et al. (2015). Spatial variation of the gut microbiota in broiler chickens as affected by dietary available phosphorus and assessed by T-RFLP analysis and 454 pyrosequencing. PLoS One 10:e0143442. doi: 10.1371/journal.pone. 0145588

Xu, Y., Yang, H., Zhang, L., Su, Y., Shi, D., Xiao, H., et al. (2016). Highthroughput sequencing technology to reveal the composition and function of cecal microbiota in Dagu chicken. BMC Microbiol. 16:259. doi: 10.1186/s12866016-0877-2

Yang, L., Liu, S., Ding, J., Dai, R., He, C., Xu, K., et al. (2017). Gut microbiota co-microevolution with selection for host humoral immunity. Front. Microbiol. 8:1243. doi: 10.3389/fmicb.2017.01243

Yatsunenko, T., Rey, F. E., Manary, M. J., Trehan, I., Dominguez-Bello, M. G., Contreras, M., et al. (2012). Human gut microbiome viewed across age and geography. Nature 486, 222-227. doi: 10.1038/nature11053

Yeoman, C. J., Chia, N., Jeraldo, P., Sipos, M., Goldenfeld, N. D., and White, B. A. (2012). The microbiome of the chicken gastrointestinal tract. Anim. Health Res. Rev. 13, 89-99. doi: 10.1017/s1466252312000138

Zarrinpar, A., Chaix, A., Yooseph, S., and Panda, S. (2014). Diet and feeding pattern affect the diurnal dynamics of the gut microbiome. Cell Metab. 20, 1006-1017. doi: 10.1016/j.cmet.2014.11.008

Zhao, L., Wang, G., Siegel, P., He, C., Wang, H., Zhao, W., et al. (2013). Quantitative genetic background of the host influences gut microbiomes in chickens. Sci. Rep. 3:1163. doi: 10.1038/srep01163

Zhou, X., Jiang, X., Yang, C., Ma, B., Lei, C., Xu, C., et al. (2016). Cecal microbiota of Tibetan Chickens from five geographic regions were determined by $16 \mathrm{~S}$ rRNA sequencing. Microbiologyopen 5, 753-762. doi: 10.1002/mbo3.367

Zucker, I., and Beery, A. K. (2010). Males still dominate animal studies. Nature 465:690. doi: $10.1038 / 465690$ a

Conflict of Interest Statement: The authors declare that the research was conducted in the absence of any commercial or financial relationships that could be construed as a potential conflict of interest.

Copyright (c) 2018 Kers, Velkers, Fischer, Hermes, Stegeman and Smidt. This is an open-access article distributed under the terms of the Creative Commons Attribution License (CC BY). The use, distribution or reproduction in other forums is permitted, provided the original author(s) and the copyright owner are credited and that the original publication in this journal is cited, in accordance with accepted academic practice. No use, distribution or reproduction is permitted which does not comply with these terms. 